\title{
The architecture of pedagogy
}

In Europe, and Britain in particular, there is currently renewed enthusiasm for debate about the structure and content of architectural education. The Architectural Review, for example, ran a special issue on education in October 2012 as part of its 'Big Rethink' campaign. The European Union is presently revising its Professional Qualifications Directive, 'to create a new level playing field for the registration of architects across Europe' while, simultaneously, the European Association for Architectural Education, EAAE, is imploding around a series of disputes, some administrative and others ideological. In Britain, Ryder Architecture is leading a review of education in conjunction with The Architects' Journal. Meanwhile, the UK Architectural Education Review Group, associated with scHosA, the Standing Committee of Heads of Schools of Architecture, has launched its own working party on the future of learning. These diverse reviews are struggling with familiar competing ideas about architectural education: to what extent should schools produce 'practice ready' graduates or focus on inculcating the culture of the discipline; what respective weight should be accorded to technical knowledge, critical insight, sociological analysis and design speculation; and should studio projects be formulated to encourage unfettered imagination or solve real-world problems? Questions like these seem sharper at a time when the ongoing global financial crisis, and a renewed self-consciousness about professionalisation (see arq 13.2 and 15.4), seem to be increasing anxiety about the role of architecture and what it means to be an architect.

This issue of arq begins with a 'perspective' by Gordon Murray, partner in Ryder Architecture and the outgoing chair of scHosA, who speculates on the structure and purpose of architectural education in a changing society (pp. 281-84). Murray argues for a pedagogy that reflects 'the realities of industry and business and the practice of architecture' which does not neglect the long history of the discipline and its studio culture. The varied potential of creative studio culture is highlighted elsewhere in this issue by Graham Farmer and Michael Stacey, who reflect on learning which emerges from hands-on making (pp. 301-12), and by Igea Troiani, who outlines a speculative studio of a different kind, testing how post-apocalyptic ecological science-fiction novels and film can inform sustainable architectural design (pp. 313-24). Meanwhile, Mary Ann Steane, David Jolly Monge and Marcelo Araya Aravena review a pedagogical exhibition in Cambridge, conceived in an international collaboration between architecture schools (pp. 325-37). 
For all the knowledge, wisdom and creative experience that schools offer their students, it is buildings themselves that arguably have the most to teach architects about architecture. The best buildings are intensely pedagogical. Peter Carolin addresses here the ethos and projects of John Voelcker, a member of Team 10 whose thoughtful approach remains an example (pp. 363-76). Voelcker's architecture and the culture of his office, Carolin illustrates, is quietly but deeply instructive about what architecture can achieve. Amid various calls for urgent change in architectural education, and various speculations about what a future profession should be like, it should be remembered that the values embodied in good buildings can not only teach architects about design, but teach society about how much architecture has to offer it.

THE EDITORS 